\title{
EFFECT OF TOOL SHAPES ON MRR AND TWR IN DIE SINK EDM
}

\author{
MR. MOSHIM GULAB MULLA ${ }^{1}$, DR. ANSHUMAN KUMAR ${ }^{2}$, MR. MUKUND KAVADE ${ }^{3}$ \& \\ ROHIT GHULANAVAR \\ ${ }^{1,4}$ Research Scholar, KLEF, Vijayawada, AP, India \\ ${ }^{1,4}$ Assistant Professor, Department of Mechanical Engineering, SGMCOE, Mahagaon, Gadhinglaj, MS, India \\ ${ }^{2}$ Associate Professor, Department of Mechanical Engineering, KLEF, Vijayawada, AP, India \\ ${ }^{3}$ Associate Professor, Department of Mechanical Engineering, RIT, Islampur, India
}

\begin{abstract}
Aim of this work is to study the effects of tool shapes with its size in Die Sink Electric Discharge Machining (EDM) Process. To explain effects of machining factors like, discharge current, pulse on-time, pulse off-time, and tool area with various tool size and shapes like Rectangular, Circular, Square, U-Shape, and Triangular on Material Removal Rate (MRR) and Tool Wear Rate (TWR) in EDM. This paper presented in three sections, first details about the EDM process and its important aspects, second section contains overview of various studies carried out with considering tool shapes as a factor in Die Sink EDM process, and last section gives comparative study of the various tool shapes used in EDM which is useful to others to select best tool shape while doing further research in same field.

KEYWORDS: Tool Shapes, EDM Process, MRR, TWR, etc
\end{abstract}

Received: Jun 10, 2020; Accepted: Jun 30, 2020; Published: Jul 16, 2020; Paper Id.: IJMPERDJUN2020353

\section{INTRODUCTION}

Thermal erosion is one of the name of EDM in which material removal is done by series of electric sparks in between two electrodes i.e. tool and work piece, which are surrounded by dielectric fluid. Pressurised dielectric fluid is used for flush and washes the fine metal particles from the gap between tool and work piece. Main application of EDM is to machine hard materials or difficult to machine materials and high strength temperature resistant alloys. Correct choice of the parameters is crucial role for getting better results from EDM process to fulfill high accuracy and dimensional tolerance demands field like aerospace, dies, etc.

\section{Principle of EDM}

Rapidly recurring sparks between two electrodes creates melting and vaporization of material which leads to material removed from work piece. This is in very small size like micron. Figure 1.1 shows EDM machine setup, for maintaining small gap (about $0.025 \mathrm{~mm}$ ) between two electrodes servo system is used. Liquid dielectric fluids like, EDM Oil, Kerosene and Deionised water are commonly used. Work piece and tool are dipped into dielectric fluid while machining goes on. [1][2][12]

\section{Abbreviations}

- $\quad \mathrm{EDM}-$ Electric Discharge Machining

- $\quad$ MRR - Material Removal Rate 
- $\quad$ TWR - Tool Wear Rate

- Ton - Pulse On Time/Duration

- $\quad$ Toff - Pulse Off Time/Duration

- $\quad$ RSM - Response Surface Methodology

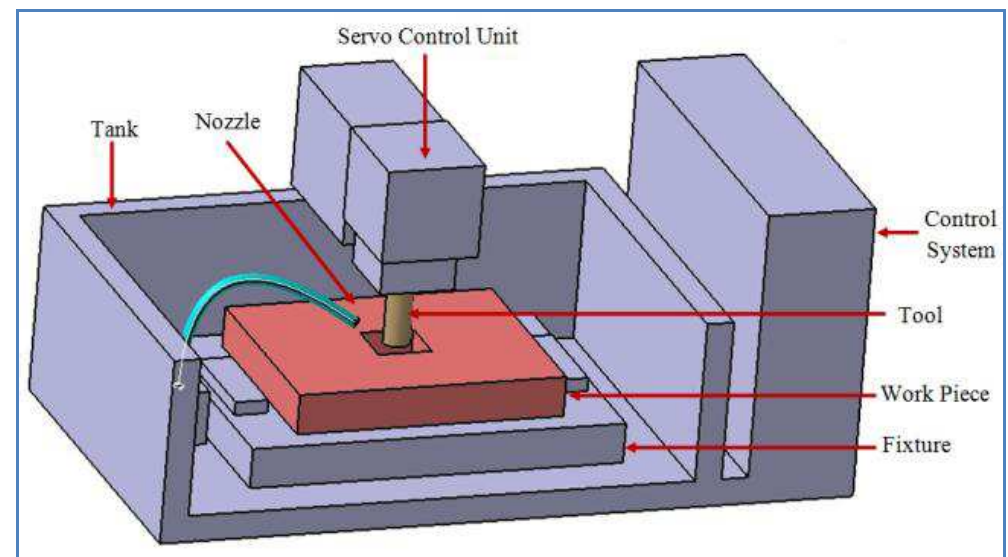

Figure 1: Set Up of EDM Machine [12].

\section{Classification of EDM Machining on the Basis of Working Principal}

- $\quad$ Die Sink Type EDM

- Wire Cut Type EDM

And, the difference between them is shown in below figure,

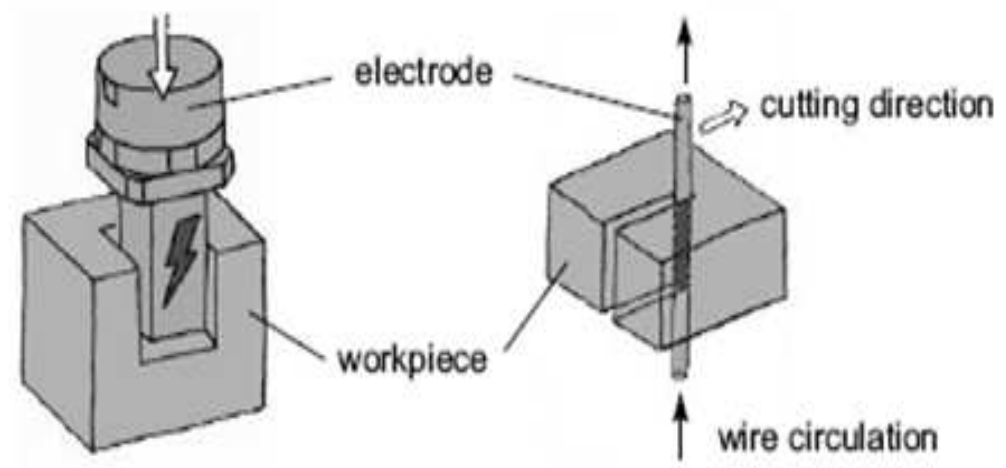

Figure 2: EDM Types - Die Sinker and Wire Cut.

\section{PREVIOUS STUDIES ON TOOL SHAPES}

Lot of researchers were worked on EDM technique and good results are get by optimum setting of parameters but only few studies was reported with considering Tool shape factor. Some of them are as, Sohani et al. [4] done comparative study of different tool shapes and size in EDM and conclude that circular shape tool gives best results than other three type of shapes.

Ashok Kumar [5] proposed that, the current increases the MRR is also increases but when the pulse on increases the MRR is decreasing monotonically. So if we want to improve the rate of MRR we have to decrease the Pulse on time. 
Finally concluded that MRR is not depend on the dia. of electrode and current is most effected parameter on TWR, then pulse on time and last diameter of tool.

T.C. Bhagat [6] done investigation on surface roughness with Copper-Tungsten electrode on die steel and concluded that current is main factor with contribution of 3.018 on surface roughness in EDM.

Jagdeep Singh [7], investigates Material Removal Mechanism and the Thermal Aspects in the EDM Process. The surface roughness increased as the peak current and pulse on time increased using the reverse polarity. And MRR is less in reverse polarity as compared to straight polarity in process.

N.Arunkumar [8] done investigation in EDM with EN31 using three different tool materials namely copper, aluminium and EN24, and also the problems involved in using graphite and brass as tool material.

D Sudhakara [9] from his study he proposed that, increments in the current, spark intensity increases therefore surface roughness and MRR also increased. But due to high spark intensity, deplete carbon layer which results hardness of the work piece material is decrease.

Zhon and Han [10] proposed novel technique for auto regulating down time of the tool known as EDM adaptive control system has been developed and this system gives stable machining and best results appox.100\% improvement in machining rate than without adaptive control.

\section{TOOL SHAPES USED}

While machining in Die sink EDM different types of tool shapes are used some of types is as follow;

- Circular

- Triangular

- Rectangular

- Square

- U-shaped

- $\quad$ Diamond

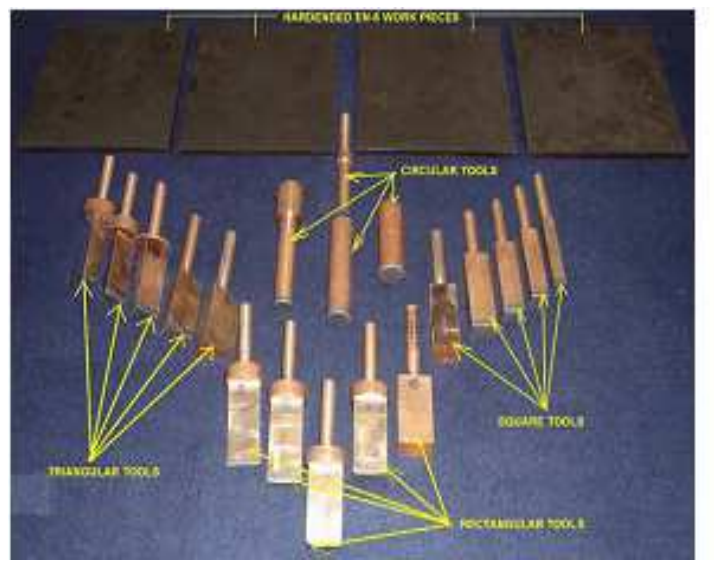

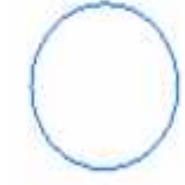

Round

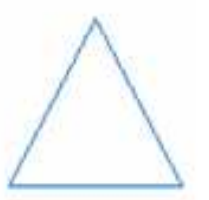

Triangular

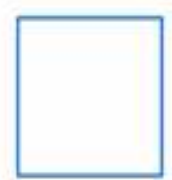

Square

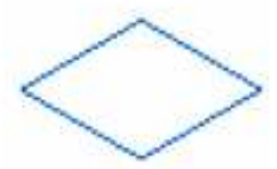

Diamond

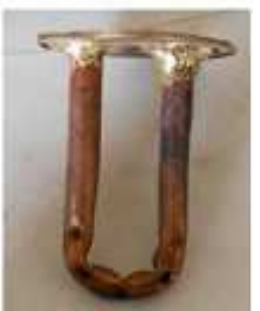

Figure 3: Shapes of Tool Used in EDM [4] [5] [16]. 


\section{Important Parameters and Its Effect on MMR and TWR with Various Shape Tools}

Discharge current: Below figure shows the relation between discharges current (I) and MRR for various tool shapes. This is direct proportional type, current increases MRR also Increases. From the graph it is clear that circular shape tool gives better MMR as increment in discharge current than other tool shapes. Below graphs is drown by Sohani [4] and Ahsan Ali Khan [16] conducting experiment on Die sinker EDM machine.
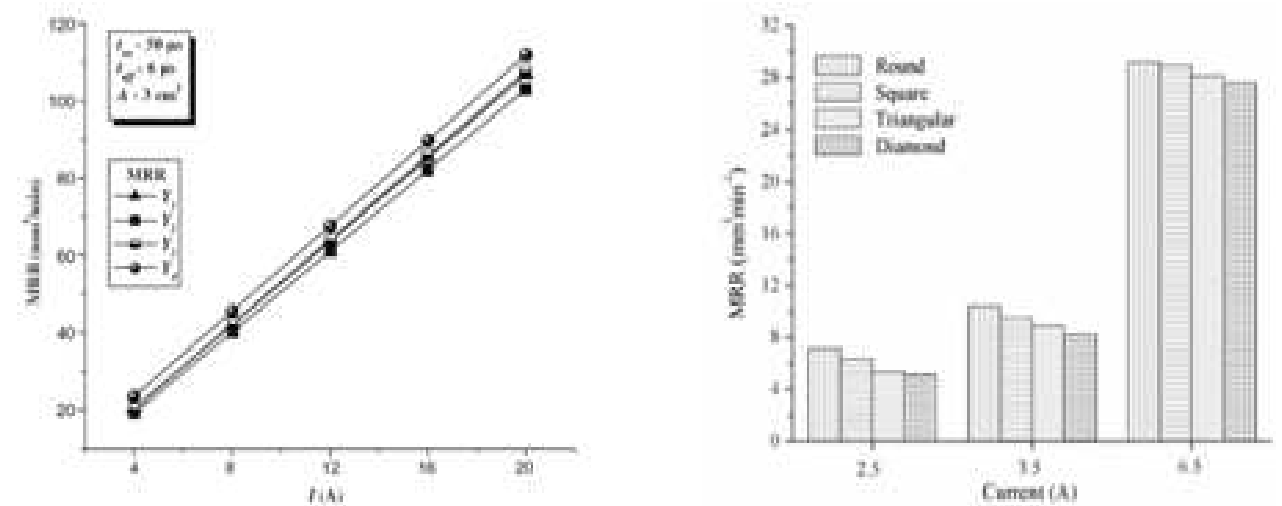

Figure 4: Discharge Current Effect on MRR [4] [16].

Relation between current and TWR for various tool shapes as show in below figure. Relationship shows increase in current, TWR also increases and square shape tool gives more TWR as compared to others.
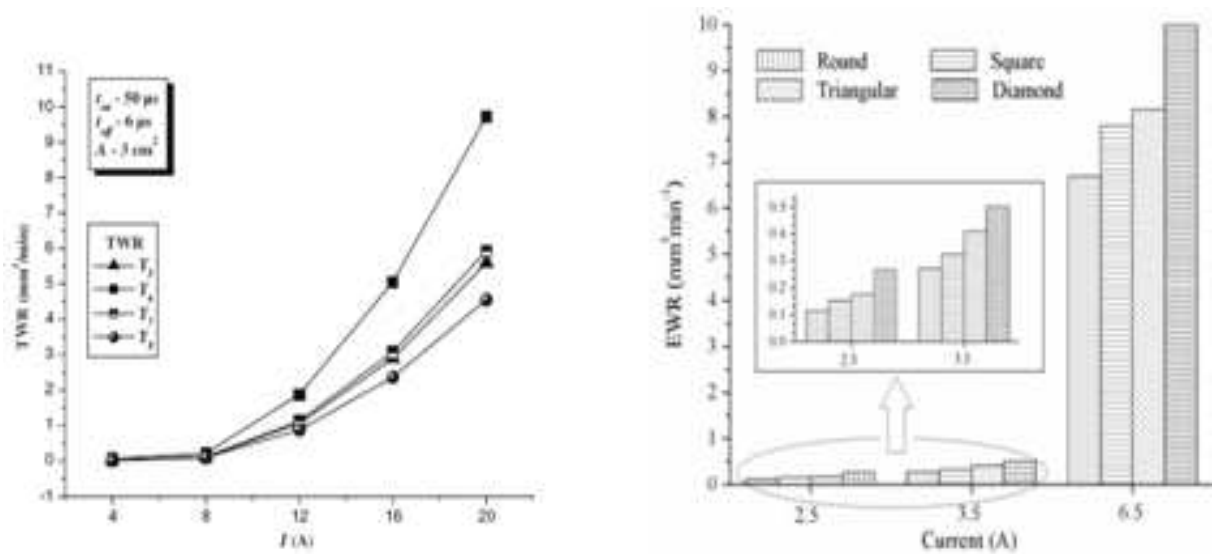

Figure 5: Discharge Current Effect on TWR [4] [16].

From the above graph it is clear that discharge current is the most influences on MRR and TWR i.e. increase in current MRR and TWR also increases. And relationships are linear for MRR and nonlinear for TWR. This is happed due to, if current increased then pulse energy also increases which leads to increments in rate of heat energy which is associated with both electrodes. Therefore melting rate and evaporation also increases that is nothing but MRR increases.

For U-shape type tool, relationship between discharge current and MRR is shown in below graph which was drowning by Ashok Kumar et.al in his study. Also he has found that initially MRR is improving while increasing current, because of more erosion of work piece material and after certain increment in current MMR starts reducing. This is due to metallurgical electrode i.e. Tool starts net deposition on work piece material. 


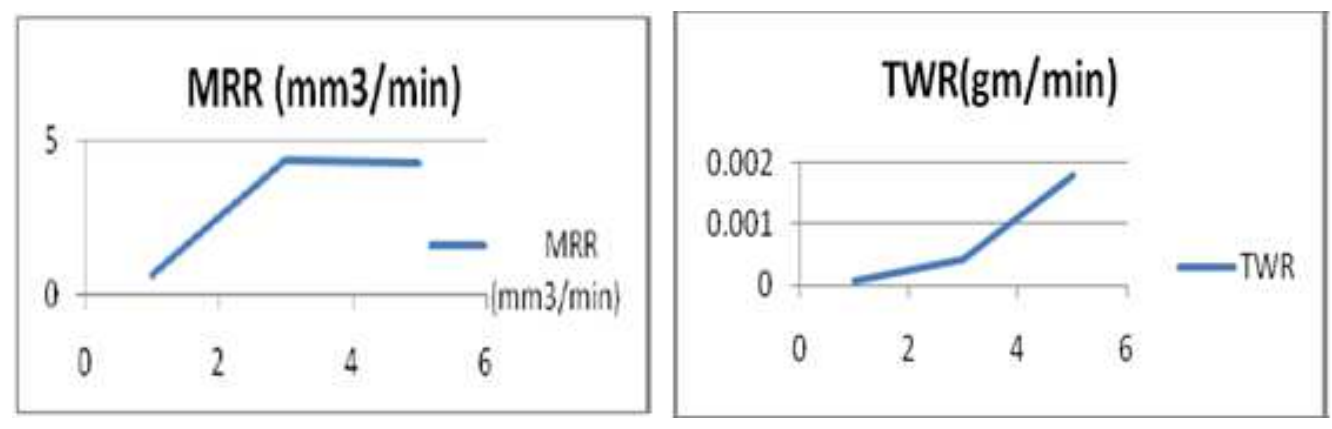

Figure 6: Current (Ip) Effect on MRR and TWR [5].

Spark On-time: denoted as Ton and is nothing but duration of time in micro second ( $\mu \mathrm{s})$, the current is allowed to flow per cycle and also known as pulse time. Relation between Pulse time (Ton) and current for different tool shapes is as shown in below fig. No.3.5. Below graphs clearly shows that, Initially MRR increases with increasing Ton, after curtain limit there is reduction in MRR. And MRR is higher for circular shape tool than other types. While increasing Ton, TWR gradually decreases and TWR is more for square type tool as compared to other types of tools. (As shown in fig.No.3.5)
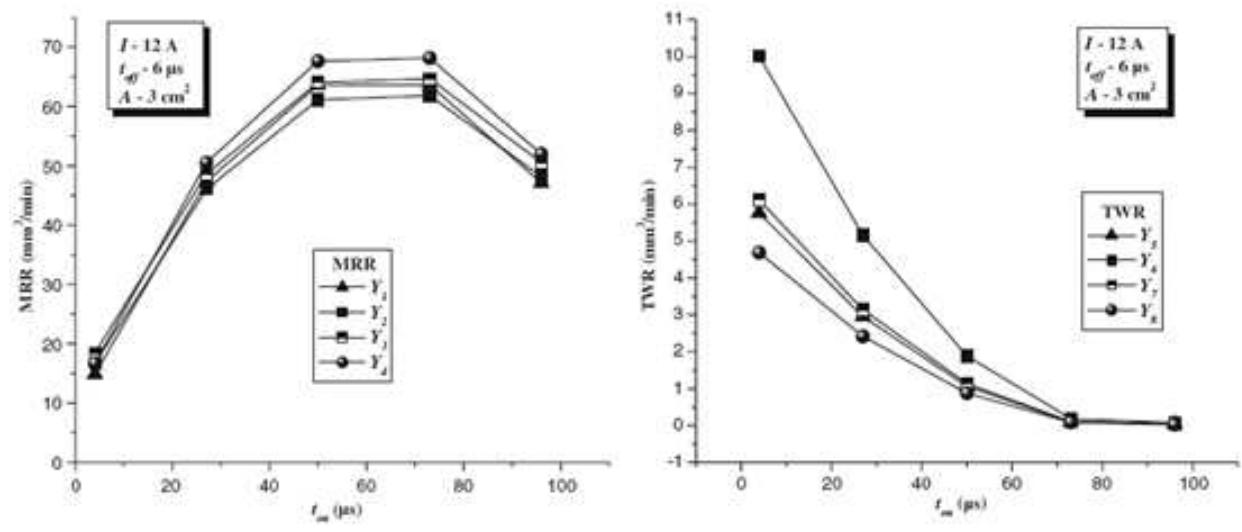

Figure 7: Ton Effect on MRR and TWR [4].

\section{COMPARISON STUDY}

From the all previous studies with considering shape of tool it is clear that Circular shape giver better result to improve MRR and reduce TWR. Rectangle and diamond shape tools gives less MRR and more TWR. This is due those sharp corners in it. Therefore it is clear sign of indication that less sharp corners tool gives better results to improve MRR and less TWR. But in this respect no more studies are done and there is gap of research, which is the main aim of this paper.

\section{CONCLUSIONS}

In the present study, MRR and TWR behaviour are studied with considering input parameters as tool shapes. And it is seem that consideration of tool shapes factor is one important parameter while optimizing processes parameter in EDM because shape of tool with size factor consideration also affects on MRR and TWR.

On parametric analysis it is clear that discharge current is most influencing factor than other factors and effects on responses is increase in current MRR and TWR also increases.

Form above study it is concluded that the best tool shape is circular for higher MRR and lower TWR than other tool shapes (i.e. Triangular, Rectangular, Diamond, Square and U-shape cross sections). Tool shape with size factor affects on responses in EDM process, therefore there is requirement of further studies with considering various tool shapes like, 
elliptical, oval, pentagon, octagon, etc. Till today there is no any research work done in same field and possibilities of better results than present tool shapes.

\section{REFERENCES}

1. Dr. P. K. Sharma Test Book of Production Technology (Manufacturing Processes). S. Chand, p 568 (2012)

2. M.S. Sohani \& V. N Gaitonde \& B. Siddeswarappa \& A. S. Deshpande "Investigations into the effect of tool shapes with size factor consideration in sink electrical discharge machining (EDM) process". Int J Adv Manuf Technol (2009) 45:1131-1145, 28 April 2009

3. Ashok Kumar, kuldeep Singh Bedi, Karaj Singh Dhillo, Rashpal Singh/International Journal of Engineering Research and Applications (IJERA) "Experimental Investigation of Machine parameters For EDM Using U shaped electrode of EN-19 tool steel” Vol. 1, Issue 4, pp.1674-1684(2010)

4. T.C. Bhagat1, H.S.Payal and B.L. Sethi "Optimizations of EDM process parameters for surface roughness machining die steel using copper tungsten electrode by adopting Taguchi array design” Indian Journal of Science and Technology Vol:5 Issue:10 October 2012 ISSN:0974-6846

5. Jagdeep Sing, Vinod Kumar "Investigation on the Material Removal Mechanism and the Thermal Aspects in the Electrical Discharge Machining Process" International Journal of Engineering and Technology Volume 2 No. 9, September, 2012

6. N.Arunkumar , H.Shareef Abdur Rawoof and R.Vivek "Investigation on the Effect Of Process Parameters For Machining Of EN31 (Air Hardened Steel) By EDM” International Journal of Engineering Research and Applications (IJERA) Vol. 2, Issue4, July-August 2012, pp.1111-1121

7. D Sudhakara, B Venkataramana Naik and B Sreenivasulu "The Experimental Analysis Of Surface Characteristics Of Inconel718 Using Electrical Discharge Machining” International Journal of Mechanical Engineering and Robotics Research, Vol. 1, No. 3, October 2012

8. Zhou, M. And Han, F. "Adaptive control for EDM process with a self-tuning regulator" International Journal of Machine Tools and Manufacture, 49(6), 462-469 (2009).

9. Anand Pandey, Shankar Singh (2010) "Current research trends in variants of Electrical Discharge Machining: A review" International Journal of Engineering Science and Technology Vol. 2(6), 2010, 2172-2191

10. Moshim Gulab Mulla, Anshuman Kumar, "Effect of Carbon Nano Tube Addition with Dielectric Fluid in Die Sink EDM" International Journal of Innovative Technology and Exploring Engineering (IJITEE) ISSN: 2278-3075, Volume-9 Issue-2, December 2019

11. Shishir Mohan Shrivastava, Dr. A.K.Sarathe, "Influence of Process Parameters and Electrode Shape Configuration On Material Removal Rate, Surface Roughness And Electrode Wear In Die Sinking EDM: A Review” International Journal of Emerging Technology and Advanced Engineering, Volume 4, Issue 4, April 2014

12. S.S. Mendhe, M.J. Deshmukh and S.S. Baraskar, "P Effect of Different on Performance Measure in EDM Process: A Review" International Journal of Modern Trends in Engineering and Research, Volume 02, Issue 02, February 2015

13. Abhijeetsinh V Makwana, Kapil S Banker, "An Electrode Shape Configuration on the Performance of Die Sinking Electric Discharge Machine (EDM): A Review” Journal of Engineering Research and Applications, Vol. 4, Issue 11(Version - 5), November 2014, pp.117-122 
14. Ahsan Ali Khan, Mohammad Yeakub Ali and Md. Mohafizul Haque "A Study of Electrode Shape Configuration on the Performance of Die Sinking EDM” International Journal of Mechanical and Materials Engineering (IJMME), Vol. 4 (2009), No. 1, 19 -23.

15. Bhola Jha, K.Ram and Mohan Rao, "An overview of technology and research in electrode design and manufacturing in sinking electrical discharge machining” Journal of Engineering Science and Technology Review 4 (2) (2011) 118-130

16. M. M. Jamadar, M.V. Kavade, "Effect Of Aluminium Powder Mixed Edm on Machinin Characteristics of Die Steel (AISI D3)" International Journal of Mechanical And Production Engineering, ISSN: 2320-2092, Volume- 2, Issue-8, Aug.-2014

17. Mukund V. Kavade, Suhas S. Mohite, Deepak R. Unaune, "Application of metal powder to improve metal removal rate in Electric Discharge Machining” Materials Today: Proceedings 16 (2019) 398-404

18. Matheswaran, M., and P. Suresh. "Study of EDM Process Parameters of Surface Roughness in Titanium Using Taguchi Method." International Journal of Mechanical and Production Engineering Research and Development (IJMPERD) 4.2 (2014): 59-64.

19. Dewan, P., and B. Pradhan. "Parametric Optimization of Powder EDM Process using Grey Relational Analysis and TOPSIS." International Journal of Applied Engineering Research and Development (IJAERD) 4.5 (2014): 1-18.

20. Bhengra, M., et al. "A Parametric Experimental Design Study of Abrasive Water Jet Machining." International Journal of Mechanical Engineering (IJME) 5.4 (2016):1-8

21. Ahmad, M. Mustafaiz, et al. "Optimization of Process Parameters in Electric Discharge Machining Process." International Journal of Mechanical Engineering (IJME) 5.4 (2016): 45-52.

22. Agarwal, Neeraj, Nitin Shrivastava, and M K Pradhan. "EDM Parameters Optimization on Tool Wear Rate Using Advanced Optimization of Titanium Alloy." International Journal of Mechanical and Production Engineering Research and Development (IJMPERD) 9.4 (2019):831-838 

